\title{
REFERENCE
}

\section{Alll06 04042己}

NIST PUBLICATIONS
A Critical Review of Measurement Practices for the Determination of $\mathrm{pH}$ and Acidity of Atmospheric

Precipitation

George Marinenko and William F. Koch Center for Analytical Chemistry National Bureau of Standards Washington, D.C., 20234
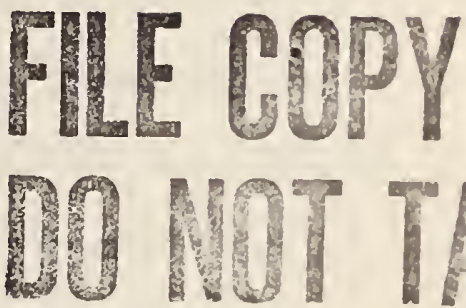

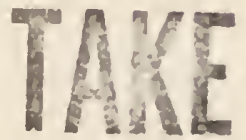

This review surveys current literature on the measurement of $\mathrm{pH}$ and acidity of atmospheric precipitation.

Current practices for calibrating $\mathrm{pH}$ measuring systems for atmospheric precipitation applications are reviewed and possible sources of error are discussed. Determinations of acidity are grouped in accordance with the type of end-point selected for titration: color indicator, fixed $\mathrm{pH}$, Gran plot, and closed loop.

Key words: acidity, acid precipitation, acid rain, acidimetric end-point, $\mathrm{pH}$ determination, $\mathrm{pH}$ standards, $\mathrm{pH}$ measurement errors, titrimetric errors.

\section{INTRODUCTION}

The purpose of this paper is to review the procedures that are

being used to measure two of the more controversial rainwater parameters,

$\mathrm{pH}$ and acidity. It is generally recognized that even uncontaminated

rainwater is naturally acidic because of the dissolved atmospheric

carbon dioxide. In the absence of any acidic components other than

atmospheric $\mathrm{CO}_{2}$, the $\mathrm{pH}$ of rain would be $5.7[1,2]$. However it is

unlikely that this laboratory ideal is ever encountered in nature, even

in remote areas, due to the natural sulfur and nitrogen cycles.

The intense concern in the last decade over acid precipitation is

not focused on the innate acidity of the precipitation, but rather on

the acid-forming components other than $\mathrm{CO}_{2}$. Of particular concern are

QC 

in the natural balance [1]. Many of these components are derived from combustion processes and are dependent on the nature and origin of the fuel used. The most prevalent among the acidic components of combustion products are oxides of sulfur, oxides of nitrogen, and hydrogen chloride.

The current literature contains many generalizations and conclusions about the trends in precipitation acidity, its possible sources (and origin), as well as projections of the environmental effects in the future [1]. Such conclusions, however, must be based on accurate analytical data. Consequently this 1iterature review was undertaken to evaluate critically the published procedures for the measurement of $\mathrm{pH}$ and acidity of atmospheric precipitation, and to assess their comparability.

\section{BACKGROUND}

Only in very special cases can the two parameters, pH and acidity, be considered interconvertible. In the majority of cases, the $\mathrm{pH}$ of a solution cannot be readily reduced to hydrogen ion concentration (acidity) without some knowledge of the other ionic components and their concentrations in the solution, as well as an understanding of systematic errors inherent in the measurement process. Conversly the knowledge of the total acid content of the solution is not necessarily sufficient to calculate its $\mathrm{pH}$. Both of these parameters, however, play an important part in defining the state of a system.

Formally defined, $\mathrm{pH}$ is the negative logarithm to the base 10 of hydrogen ion activity. It is related by some to "free acidity", or the concentration of "free" hydrogen ions in solution [3]. Often it is conceptually defined as the negative logarithm of the effective concentration of hydrogen ion. It is known that in dilute solutions, this 

effective concentration or activity is always less than the total concentration of hydrogen ions. As the concentration approaches infinite dilution, the two quantities (activity and concentration) converge.

Total acidity, on the other hand, is the measure of the total concentration of hydrogen ions both "free" and undissociated (provided they are "acidic" hydrogen atoms) [3]. Generally, total acidity is determined by acidimetric titration with strong base.

In other words, $\mathrm{pH}$ is an intensive factor, representing the free acidity of the solution, whereas the total acidity is an extensive factor, representing the acid capacity of the system. $\mathrm{pH}$ is generally the more important factor in chemical equilibria and in kinetics; total acidity dominates in stoichiometric considerations.

\section{REVIEW OF $\mathrm{pH}$ MEASUREMENTS}

Measuring $\mathrm{pH}$ in precipitation samples may at first appear to be a straightforward procedure. In reality, differences in the metrological details of the measurement can very easily produce widely variant results, often greater than 0.5 in $\mathrm{pH}$. Current measurement practices used by acid rain researchers are quite diverse. A summary of these practices is presented in Table 1. Many articles concerned with acid rain studies make no mention of the $\mathrm{pH}$ measurement details but rather report only the measured $\mathrm{pH}$ values. Since no conclusions can be drawn from such articles regarding metrological validity of the procedures, those references are not included in this review. Many of the reported procedures are quite incomplete as can be seen from Table 1.

As evidenced by the data assembled in Table 1 there is no uniformity in the procedures used for $\mathrm{pH}$ measurements in acid precipitation measurements. While in some cases the accuracy of the measurement is at least 

considered [4], data supporting the accuracy claim are lacking. In some cases it is difficult to establish exactly what measurements were performed. The following is an example of this: "Precipitation $\mathrm{pH}$ was determined by calibrated electrode meters" [5]. This is the only statement describing the $\mathrm{pH}$ measuring instrumentation. The use of unfamiliar terminology (what is an electrode meter?) and the lack of experimental detail renders the above report virtually useless when assessing the reliability of the data.

There is a point to be made regarding the precision and accuracy of $\mathrm{pH}$ measurements. Several authors report the precision of their measurements with an implication that the accuracy is of similar magnitude. However, measurement accuracy is determined by two types of error components or uncertainties: systematic and random. In testing the repeatability of $\mathrm{pH}$ measurements, (i.e. the precision, generally expressed as the standard deviation), one is testing only one of the two error contributions, namely the random error component. Included in the systematic component are measurement biases, often quite subtle in nature and unlike standard deviations, not as amenable to mathematical computation.

The systematic error assessment in $\mathrm{pH}$ measurement is complex. One factor contributing to the difficulty of assessing systematic errors is the presence of the liquid junction between the solution to be measured and the reference electrode. The presence of this junction generates a small potential across the boundary. In itself this would not be a serious problem, since this potential would be incorporated into the calibration measurements with a standard reference solution of known pH. Unfortunately liquid junction potentials are not constant and are depen- 

dent on the nature of solutions involved. Thus, calibrating the $\mathrm{pH}$ measuring electrode system with a standard buffer solution of known $\mathrm{pH}$ does not guarantee the accuracy of $\mathrm{pH}$ measurements on the unknown. Even under ideal conditions, these biases could be as large as 0.1 in $\mathrm{pH}$, depending on the buffer used for calibration as well as the nature, ionic strength and the $\mathrm{pH}$ of the unknown solution.

To make matters even more complicated, the magnitude of these liquid junction related errors is also dependent on the type of liquid junction involved (e.g. ceramic plug, flowing, etc.), on the condition of the junction, and on the history of the electrode (types of solutions tested with the electrode).

For these reasons it is advisable for the electrode systems used in acid rain $\mathrm{pH}$ work to be used exclusively for this task and to be monitored with respect to their performance with known reference solutions intended to simulate the unknown samples. However, for documentation purposes, calibration with the certified buffer solution is essential.

In addition to liquid junction potential errors, streaming potential errors can be produced by stirring or agitating the test solution during the $\mathrm{pH}$ measurement. The magnitude of this streaming potential depends on several factors: (a) type of reference electrode junction; (b) rate of stirring; and (c) ionic strength of solution. Galloway [6] and Koch [7] have observed that stirring low ionic strength solutions can produce apparent changes as large as $0.5 \mathrm{pH}$. To eliminate such errors, it is generally recommended that $\mathrm{pH}$ measurements be made in quiescent solutions $[6,7,8]$.

Galloway, Cosby and Likens [9] point out difficulties associated with accurate electrometric measurements in low ionic strength solu- 

tions, such as atmospheric precipitation. Their calculations show that if activity coefficients, liquid junction potentials, streaming potentials and non-Nernstian behavior of the electrode system are ignored, errors of $50 \%$ or more may be encountered in calculating hydrogen ion concentration. According to Galloway et al., residual liquid junction potentials, arising mainly from the differences between ionic strengths of the calibration buffer solutions and those of the samples, can produce errors as large as $0.04 \mathrm{pH}$. Koch, Marinenko, and Stolz observed even larger residual liquid junction potentials in a systematic study of various junction materials [7].

In 1979, in an attempt to reduce the effect of residual liquid junction potentials, Galloway et al. [9] recommended using solutions made from strong acids for caltbrating the glass/reference electrode system. The use of dilute solutions of strong acids along with a double junction reference electrode has been recommended by Liljestrand and Morgen [10] for calibrating the glass electrode system. The use of dilute acid calibrants tends to minimize the junction potential effects. In such a calibration approach the structure of the liquid junction between the reference electrode and calibrant solution matches more closely the junction between the reference electrode and the unknown. Three years later, in 1982, Galloway et al. [6] suggested a different procedure for $\mathrm{pH}$ measurement. Instead of using strong acid solutions to calibrate the $\mathrm{pH}$ meter, a two point calibration procedure using $\mathrm{pH} 7.00$ and $\mathrm{pH} 4.00$ buffers is used. The performance of the $\mathrm{pH}$ measurement system was periodically checked using a dilute $\mathrm{H}_{2} \mathrm{SO}_{4}$ solution of known concentration. This is in keeping with the recommendations of koch and Marinenko [11]. A similar procedure was developed by Peden et a1. [12\} 

for the U.S. Department of Energy. In their procedure, $\mathrm{pH} 7$ and $\mathrm{pH} 4$ buffers are used to calibrate the $\mathrm{pH}$ meter and a 2 min equilibration period is required before the $\mathrm{pH}$ measurement is made.

Some researchers use an inert atmosphere such as nitrogen [13] to shield the solution from atmospheric $\mathrm{CO}_{2}$. Shielding, however, is not the only effect of such a practice. Gas/solution exchange processes are relatively fast and therefore nitrogen shielding will remove some or all of the dissolved $\mathrm{CO}_{2}$, depending on the time involved and the $\mathrm{pH}$ of solution. Below $\mathrm{pH} 5$ removal of $\mathrm{CO}_{2}$ is rapid while at $\mathrm{pH} 7$ it is rather slow.

Some procedures invoke the British Standard $[14,15]$ which recommends adding $\mathrm{CuSO}_{4}$, as a fungicide, to rainwater samples at the time of collection. Adding this salt will invariably affect the acid-base equilibrium.

In one instance, a colorimetric method was employed [16] for the determination of $\mathrm{pH}$ in single drops of rain. Colorimetric $\mathrm{pH}$ indicators were sprayed on paper and calibrated with solutions of known $\mathrm{pH}$. This is, however, a special application. In general, the interest in $\mathrm{pH}$ of rain is on the bulk scale rather than on the drop size scale. The colorimetric determination of $\mathrm{pH}$ on the bulk sample may have some merit. However, a narrow range, accurate, calibration scale of sufficient sensitivity must be developed. Furthermore, colorimetric procedures are generally more involved and time-consuming than electrometric procedures.

There appears to be one point of consensus: the majority of researchers who use electrometric measurements prefer combination electrodes $[4,7,17,18,19,20]$. 

The diversity of $\mathrm{pH}$ measurement practices is quite apparent, which may be partially or wholly responsible for some of the conflicting conclusions of researchers in the area of acid precipitation. A more uniform approach to measuring $\mathrm{pH}$ in precipitation is desirable to eliminate some of the ambiguities. A self-consistent system should be developed, which will require specific standard solutions for calibration, and will specify the minimum performance characteristics of the electrodes.

\section{TOTAL ACIDITY}

The measurement of total acidity generally involves titrating acids in the sample with a standard solution of sodium hydroxide. In some cases, the standard base is generated coulometrically in situ. The methodologies employed in acid precipitation measurements of total acidity are summarized in Table 2. The principal distinction between these different experimental approaches is the manner in which the titration end-point is determined.

Three different end-point techniques are used:

(1) visual, using color indicators

(2) electrometric to a fixed $\mathrm{pH}$

(3) electrometric using Gran plot [21]

The simplest and most convenient technique for field work requires a color indicator [15]. Corrections must be made for the difference between the volume of titrant consumed to cause the color change of the indicator and the volume required to reach the equivalence point.

It is quite common to use a glass electrode while titrating to a fixed pH. Examples of this technique are illustrated in Table 2 by entries 5, 6 and 7. The choice of the end-point ranges from pH 7 to 

$\mathrm{pH}$ 9.5. Depending on the end-point $\mathrm{pH}$ value, the amount of titer will vary. First, there is a certain amount of reagent required to change the $\mathrm{pH}$ of pure water from the neutrality point to some $\mathrm{pH}$ value above it, the end-point. Naturally, the higher this end-point $\mathrm{pH}$ value, the more reagent will be required.

Second, if the end-point $\mathrm{pH}$ value is too low, not all acids present will be titrated. Only the strong acids will be completely titrated at $\mathrm{pH} 7$; the weak acids will be partially titrated. Carbonic acid is one of these weak acids. In all these procedures, valid corrections must be applied to reconcile the differences between the end-point $\mathrm{pH}$ and the equivalence point $\mathrm{pH}$. The existing nonuniformity in establishing the end-point $\mathrm{pH}$ is perhaps the single most serious variable in total acidity determinations. There is little doubt that the total acidity value obtained when titrating a sample to $\mathrm{pH} 7$, will be quite different from that obtained by titrating the same sample to $\mathrm{pH} 9.4$ (Methods 6 and 7 , Table 2) .

The Gran plot technique requires that $\mathrm{pH}$ measurements be made after several (well spaced) aliquots of standard $\mathrm{NaOH}$ solution are added to the sample. Then $\mathrm{dV} / \mathrm{dpH}=\mathrm{f}(\mathrm{V})$ can be calculated. This function is then extrapolated to the abscissa. The use of a Gran plot is one convenient way of manipulating titration data and may enable one to determine the strong acid contribution to the total acidity.

The closed loop technique provides a rapid and convenient way of obtaining the total acidity [7]. In this technique, an electrolyte solution is first adjusted to some convenient $\mathrm{pH}$ value before a measured amount of sample is introduced and titrated coulometrically to the same pH. A convenient system involves the use of $0.01 \mathrm{~mol} / \mathrm{L}$ sodium citrate solution as the electrolyte. 


\section{CONCLUSIONS}

Measuring $\mathrm{pH}$ and total acidity in low ionic strength solutions, such as acid precipitation, is a formidable task involving intrinsic difficulties associated with the measurement system (such as residual liquid junction potential, and choosing an equivalence point, respectively) even under a relatively constant set of conditions. If measurement conditions vary or if they are not given, as is indicated by the reviewed literature, the matter becomes complicated even further, to a point where no significant correlation can be made between the results of different experiments.

A uniform approach to the determination of $\mathrm{pH}$ and total acidity of precipitation is necessary to make all measured values comparable. This approach must include a sampling protocol, sample storage and handing conditions, traceability to national calibration standards (such as Standard Reference Materials issued by NBS), minimum performance requirements of all measurement instrumentation, and a valid statistical evaluation.

\section{ACKNOWLEDGMENT}

Portions of this work were funded by the United States Environmental Protection Agency, Contract Number IAG-AO-13-F-2-535-0, Subagreement 3. 

Table 1. pH Measurement Practices.

Method/Instrumentation ${ }^{*}$

1. Electrometric/Sargent-

Welch PBL combination

electrode

2. Electrometric/Corning

12 or Orion 801

instrumentation $1 \mathrm{ab}$. com-

bination, Corning glass

and Orion 90-01-00 refer-

ence electrodes

3. Electrometric/Sargent-

Welch PBL combination

electrode

4. Electrometric/glass

electrode with double

junction reference

electrode

5. Electrometric/Corning

$12 \mathrm{pH}$ meter with

combination electrode

6. Colorimetric/indicators

sprayed on paper
Calibration

Remarks

Ref

Accuracy

[4]

claimed

$+0.03 \mathrm{pH}$

$\mathrm{N}_{2}$ atmosphere

"dilute acid

solutions"

Fisher certi-

fied $\mathrm{pH} 4.00$

and $\mathrm{pH} 7.00$

buffers

"calibration with

solutions of known

$\mathrm{pH}^{\prime \prime}$ 

Table 1 (Continued).

Method/Instrumentation * $+$

7. Electrometric/Orion

standard buffers

combination electrode

$\mathrm{pH} 4.0$ and

$\mathrm{pH} 9.2$

8. Electrometric

standard buffer

standard devi-

$\mathrm{pH} 4.00$ and ation of mea-

$\mathrm{pH} 7.00$ surement is

$0.05 \mathrm{pH}$

9. Electrometric

Dilute solutions

of strong acid

10. Electrometric/com-

$\mathrm{pH} 4.004$ NBS buffer

bination electrode

pH 6.863 NBS buffer

with ceramic junction

\footnotetext{
* Certain commercial equipment, instruments, or materials are identified in this report to specify adequately the experimental procedure. Such identification does not imply recommendation or endorsement by the National Bureau of Standards, nor does it imply that the materials or equipment identified are necessarily the best available for the purpose.
} 

Table 2. Total Acidity Measurements.

Titration method

1. Microtitration of $5 \mathrm{~mL}$

sample with $\mathrm{NaOH}$

solution

2. Conventional $\mathrm{NaOH}$

titration

3. Conventional $\mathrm{NaOH}$

titration

4. Coulometric generation

of $\mathrm{OH}^{-}$

5. Conventional $\mathrm{NaOH}$

titration

6. Conventional $\mathrm{NaOH}$

titration

7. Titration with

$5.10^{-3} \mathrm{~mol} / \mathrm{L} \mathrm{NaOH}$

8. Conventional $\mathrm{NaOH}$

titration

9. Coulometric titration
End-Point

Remarks

Ref.

Electrometric/

Gran Plot

Electrometric/

[22] [29]

Gran P1ot

Electrometric/

Gran Plot

Resolution of

strong and weak

acid contributions

Modified Gran plot

[7][23][24][27

or closed loop

$\mathrm{pH}=9$

$\mathrm{CO}_{2}$ has large

[3] [4] [18]

effect on acidity

$\mathrm{pH}=9 \cdot 4-9.5$

$\mathrm{N}_{2}$ purging to re-

move $\mathrm{CO}_{2}: \mathrm{NaOH}$

standardized with

KHP

color indicators;

electrometric/

Gran Plot

closed loop pH 8.3 

[1] Acid Rain, [Rep] EPA 1980, EPA-600/9-79-036, 1-36.

[2] Magnuson, J. J.; Rehel, F. J.; Talbot, M. J.; Forbes, A. M.; Medrick, P. A. [Rep] EPA 1980, EPA-600/3-80-078, 1-100.

[3] Galloway, J. N.; Likens, G. E.; Edgerton, E. S. Water, Air, and Soil Pollution, 1976,6 , 423-433.

[4] Galloway, J. N.; Likens, G. E.; Edgerton, E. S. Science, 1976, 194, $722-723$.

[5] Richardson, C. I.; Merva, G. E. Proc. First Internat. Sympos. on Acid Precipitation and the Forest Ecosystem, 1975, 321-332.

[6] Galloway, J. N.; Likens, G. E.; Keene, W. C.; Miller, J. M. J. Geophys. Research, 1982, 87, 8771-8786.

[7] Koch, W. F.; Marinenko, G.; Stolz, J. W. Simulated Precipitation Reference Materials, IV, 1982, NBSIR 82-2481.

[8] Madsen, B. C. Atmos. Environ., 1981, 15, 853-862.

[9] Galloway, J. N.; Cosby, B. J.; Likens, G. E. Limnol. and Oceanogr., $1979, \underline{24}, 1161-1165$.

[10] Liljestrand, H. M.; Morgen, J. J. Environ. Sci. and Tech. 1978, 12, $1271-1273$

[11] Koch, W. F.; Marinenko, G. Proc. Sympos. on Sampling and Analysis of Rain, Amer. Soc. Testing and Matls., Philadelphia, PA. 1983.

[12] Peden, M. E.; Skowron, L. M.; McGurk, F. F. Precipitation Sample Handling, Analysis and Storage Procedures, 1979, c00-1199-57.

[13] Brosset, C.; Ferm, M. Atmospheric Environment, 1978, 12, 909-916.

[14] Martin, A. The Science of the Total Environment, 1979, 13, 119-130. 

[15] BSI British Standard 1747, Methods for the Measurement of Air Pollution, British Standard Institution, London, 1969.

[16] Kramer, J.; Tessier, A. Environ. Sci. and Technology, 1982, 16, $606 A-615 A$.

[17] Jacobson, J. S.; Heller, L. I.; Van Leuken, P. Proc. First Internat. Sympos. on Acid Precipitation and the Forest Ecosystem, 1975, 267-279.

[18] Galloway, J. N.; Likens, G. E.; Edgerton, E. S. Proc. First Internat. Sympos. on Acid Precipitation and the Forest Ecosystem, 1975, 383-396.

[19] Hendry, C. D.; Brezonik, P. L. Environ. Sci. and Tech. 1980, 14 , 843-849.

[20] Scott, W. D. Atmospheric Environment, 1977, 12, 917-921.

[21] Gran, G. Acta Chem. Scan., 1950, 4, 559-577.

[22] Semb, A. Water, Air, and Soil Pollution, 1976, 6, 231-240.

[23] Seymour, M. D.; Schubert, S. A.; Clayton, Jr., J. W.; Fernando, J. Water, Air and Soil Pollution, 1978, 10, 147-161.

[24] Krupa, S.; Coscio, Jr., M. R.; Wood, E. A. J. of the Air Pollution Control Assn. , 1976, 26, 221-223.

[25] Frohliger, J. O.; Kane, R. L. Proc. First Internat. Sympos. on Acid Precipitation and the Forest Ecosystem, 1975, 381.

[26] Klockow, D.; Denzinger, H. Proc. First Internat. Sympos. on Acid Precipitation and the Forest Ecosystem, 1975, 157-158.

[27] Krupa, S. V.; Coscio, Jr., M. R.; Wood, F. A. Proc. Eirst Internat. Sympos. on Acid Precipitation and the Forest Ecosystem, 1975, 371-380.

[28] Cogbill, C. V. Proc. First Internat. Sympos on Acid Precipitation and the Forest Ecosystem, 1975, 363-370. 

[29] Brosset, C. Proc. First Internat. Sympos. on Acid Precipitation and the Forest Ecosystem, 1975, 159-179.

[30] Esmen, N. A.; Fergus, R. B. The Science of the Total Environment, 1976, 6, 223-226.

[31] Keene, W. C.; Galloway, J. N.; Holden Jr., J. D. J. Geophys. Res. (in press. 

